\title{
QUALIDADE FISIOLÓGICA E SANITÁRIA DE SEMENTES DE SORGO TRATADAS COM ÓLEO ESSENCIAL DE Melaleuca alternifolia (MYRTACEAE)
}

\author{
SENEME, Adriana Martinelli ${ }^{1}$ \\ FLORES, Caroline Mariane ${ }^{2}$ \\ RUARO, Lucimeris ${ }^{3}$ \\ FERRIANI, Aurea Portes ${ }^{4}$
}

Recebido em: 2019.06.27_Aprovado em: 2020.01.24

ISSUE DOI: $10.3738 / 1982.2278 .3661$

\begin{abstract}
RESUMO: Sementes contaminadas podem introduzir patógenos em novas áreas causando prejuízos significativos na produção, tombamento, morte de plantas, podridões e infecções generalizadas. O tratamento das sementes com óleos essenciais é um método alternativo ao uso de agrotóxico que pode apresentar propriedades microbianas capazes de controlar a microflora associada às sementes. O presente trabalho teve como objetivo avaliar a qualidade fisiológica e sanitária de sementes de sorgo tratadas com diferentes concentrações de óleo essencial de Melaleuca alternifolia. Sementes de sorgo foram tratadas com soluções de óleo essencial de melaleuca nas concentrações de 0,$25 ; 0,50 ; 1,00$ e 1,50 além da testemunha e submetidas aos testes de germinação, primeira contagem da germinação, peso de matéria seca de plântula, teste de sanidade ("Blotter test") (em laboratório) e emergência em casa vegetação (logo após o tratamento e após 30 dias). O delineamento foi inteiramente casualizado, com 5 repetições para casa de vegetação e 4 repetições para o teste de germinação, as médias foram comparadas pelo teste Tukey a 5\% de probabilidade. De acordo com os resultados verificou-se que não houve efeito prejudicial às plântulas de sorgo quando a semeadura foi realizada após o tratamento das sementes; a partir da concentração de 0,50\% de óleo houve controle do Colletotrichum spp. e maior índice de sementes "limpas" (visualmente sem a presença de patógenos) e o uso das sementes após 30 dias do tratamento ocasionou redução de peso de matéria seca e altura de plântulas.
\end{abstract}

Palavras-chave: Colletotrichum. Patógenos. Tratamento. Sanidade. Alelopatia.

SUMMARY: Contaminated seeds can introduce pathogens into new areas causing significant damage to production, tipping, plant death, rot and widespread infections. The treatment of the seeds with essential oils is an alternative method to the use of pesticides that can present microbial properties capable of controlling the microflora associated with the seeds. The present work aimed to evaluate the physiological and sanitary quality of sorghum seeds treated with different concentrations of essential oil of Melaleuca alternifolia. Sorghum seeds were treated with solutions of essential oil of melaleuca at concentrations of $0.25 ; 0.50 ; 1.00$ and 1.50 in addition to the control and submitted to germination tests, first germination count, seedling dry matter weight, Blotter test (in laboratory) and emergence at home vegetation (shortly after The treatment and after 30 days). The design was completely randomized, with 5 replicates for greenhouse and 4 replicates for the germination test, the averages were compared by the Tukey test at $5 \%$ probability. According to the results it was verified that there was no harmful effect to sorghum seedlings when sowing was performed after the seed treatment. From the concentration of $0.50 \%$ of oil there was control of Colletotrichum spp. Also a higher index of "clean" seeds (visually without the presence of pathogens) and seed use after 30 days resulted in a reduction in dry matter weight and seedling height.

Keywords: Colletotrichum. Pathogens. Treatment. Sanity. Allelopathy

\section{INTRODUÇÃO}

O sorgo (Sorghum bicolor L. (Moench)) é uma gramínea pertencente à família das poáceas, é o quinto cereal mais importante do mundo, sendo usado como matéria prima de diversos seguimentos de produção (FLAVIO et al, 2014).

\footnotetext{
${ }^{1}$ Professora, Dra. Adjunto IV, Departamento Fitotecnia e Fitossanidade, UFPR

${ }^{2}$ Engenheira Agrônoma, UFPR

${ }^{3}$ Professora, Dra, Departamento Fitotecnia e Fitossanidade

${ }^{4}$ Bióloga, Dra. em Agronomia
} 
A cultura do sorgo na safra 2018/19 no país deverá ter uma área plantada de 727,8 mil hectares e uma produtividade de $2.932 \mathrm{~kg} / \mathrm{ha}$, com produção de 2.134 mil toneladas (CONAB, 2019).

Sementes contaminadas são importantes fontes de contaminação, podendo introduzir patógenos em novas áreas, e causar, além de prejuízos significativos na produção, tombamento, morte de plantas, podridões e infecções generalizadas. Além de perdas econômicas o risco de contaminações, especialmente por fungos micotoxicogênicos, é um aspecto que deve receber atenção, pois a produção de micotoxinas compromete a saúde humana e animal. Os gêneros mais frequentes que causam contaminação são Aspergillus e Fusarium, suas espécies predominantes são Fusarium verticillioides, $F$. proliferatum, Aspergillus flavus e A. parasiticus, que ocorrem em plantas comercializadas em commodities (MAIA et al., 2015).

No tratamento de sementes normalmente são utilizados agrotóxicos que podem contaminar o ambiente e comprometer a saúde humana e animal. Frente a esta situação, a sociedade vem demandando, cada vez mais, a produção de alimentos sem resíduos de agrotóxicos e com menor impacto ambiental.

Como alternativa ao uso de agrotóxicos, têm sido realizadas pesquisas com produtos naturais, como óleos essenciais e extratos hidro alcoólicos, que podem apresentar propriedades antimicrobianas capazes de controlar a microflora associada às sementes.

A utilização de substâncias naturais com ação antifúngica aparece como uma opção de baixo impacto ecológico e ambiental, podendo ser usados na proteção natural de plantas e indicado no controle de doenças provocadas por fungos e bactérias (GOMES et al., 2008). A literatura mostra resultados positivos de controle de patógenos com óleos de capim limão (Cymbopogon flexuosus) em feijão (MORAIS et al., 2008); de Melissa officionallis em soja (INÁCIO, 2009); eucalipto, capim limão e tomilho em sementes e plântulas de milho (JARDINETTI, 2011) e melaleuca em girassol (MARIANO et al., 2013).

Jardinetti et al. (2011) observaram que os óleos essenciais de eucalipto, capim limão (Cymbopogon citratus) e tomilho (Thymus vulgaris) apresentaram redução da incidência de Fusarium sp. e Aspergillus spp. em sementes e plântulas de milho. Morais et al. (2008) também realizaram o tratamento de sementes de soja utilizando óleos essenciais de Ocimum sp., Cymbopogon flexuosus, Cymbopogon citratus e Melaleuca sp. e com relação a sanidade, não foram observadas diferenças estatísticas significativas entre os tratamentos testados no controle de Fusarium sp., Penicillium sp. e Alternaria sp. indicando que esses óleos não tiveram efeito sobre controle desses patógenos. Os óleos essenciais de Cymbopogon citratus, Cymbopogon flexuosus e Melaleuca sp. reduziram a ocorrência de Phomopsis sp. nas sementes, e o óleo essencial de Cymbopogon flexuosus apresentou atividade inibitória sobre Colletotrichum sp. 
Em meio às espécies que apresentam potencialidade no combate de fungos e bactérias, está a melaleuca (Melaleuca alternifolia), também conhecida popularmente por árvore-do-chá, tea tree e árvore-ti. A melaleuca é uma árvore aromática, da família Myrtaceae e originária da Austrália, que apresenta ampla importância econômica pela presença de óleo volátil armazenado no tecido foliar (MARTINS et al., 2011).

É importante ressaltar que apesar da importância do uso de óleo essencial na agricultura sustentável, esses compostos vegetais (especialmente mono e sesquiterpenos) podem interferir nos processos fisiológicos da planta podendo prejudicar a germinação e o desenvolvimento de plântulas, razão porque devem ser avaliados os parâmetros que conferem uma boa germinação das sementes quando colocadas no campo (BIASI; DESCHAMPS, 2009). A fitotoxicidade de extratos sobre várias plantas ou demais organismos é atribuída à diversidade de aleloquímicos presentes em sua composição, os quais são originados do metabolismo secundário dos vegetais. (MAZZAFERA, 2003).

Devido à carência de informações sobre o uso de óleos essenciais no tratamento de sementes, o presente trabalho teve como objetivo identificar os efeitos de diferentes concentrações do óleo essencial de melaleuca na qualidade fisiológica e sanitária de sementes de sorgo.

\section{MATERIAL E MÉTODO}

Sementes de sorgo do cultivar XB6020 foram submetidas aos seguintes procedimentos iniciais: a) determinação do teor de água (BRASIL, 2009a); b) teste de germinação (BRASIL, 2009a) e peso de 100 sementes. (BRASIL, 2009a).

Foram coletadas folhas de árvores de Melaleuca alternifolia cultivadas na Fazenda Experimental do Canguiri, em Quatro Barras - PR, no mês de março de 2016. Após a extração do óleo por hidrodestilação as amostras foram analisadas em cromatógrafo gasoso com detector de espectro de massa para qualificação das moléculas. Para quantificação utilizou-se os padrões analíticos e amostra em cromatógrafo gasoso com detector de ionização de chamas (FID). A descrição dos componentes do óleo está na Tabela 1. 
Tabela 1. Componentes (CO) e índice de retenção (IR) de óleo essencial de Melaleuca alternifolia.

\begin{tabular}{lcclcc}
\hline CO & IR & $\%$ & CO & IR & $\%$ \\
\hline$\alpha$-tujeno & 924 & 0,65 & Linalol & 1095 & 3,42 \\
$\alpha$-pineno & 932 & 1,88 & $\mathrm{Ni}^{1}$ & - & 0,71 \\
Sabineno & 969 & 1,62 & trans- - -menth-2-en-1-ol & 1136 & 0,41 \\
$\beta$-pineno & 974 & 0,6 & terpinen-4-ol & 1174 & 45,06 \\
Mirceno & 988 & 0,37 & $\alpha$-terpineol & 1186 & 2,87 \\
$\alpha$-felandreno & 1002 & 0,21 & cis-piperitol & 1195 & 0,17 \\
$\alpha$-terpineno & 1014 & 11,35 & $\alpha$-gurjuneno & 1409 & 0,1 \\
$\rho$-cimeno & 1020 & 0,34 & Ni ${ }^{1}$ & - & 0,13 \\
Silvestreno & 1025 & 1,08 & Aromadendreno & 1439 & 0,29 \\
1,8 -cineole & 1026 & 2,55 & allo-aromadendreno & 1458 & 0,13 \\
$\gamma$-terpineno & 1054 & 19,88 & trans-cadina-1(6),4-dieno & 1475 & 0,15 \\
Ni ${ }^{1}$ & - & 0,72 & Biciclogermacreno & 1500 & 1,06 \\
Terpinoleno & 1086 & 3,2 & $\delta$-cadineno & 1522 & 0,58 \\
Ni ${ }^{1}$ & - & 0,26 & Zonareno & 1528 & 0,11 \\
1 -epi-cubenol & 1627 & 0,1 & & & \\
\hline Total & & & & & 100 \\
\hline${ }^{N}$ Na identificado & & & & &
\end{tabular}

${ }^{1}$ Não identificado

Óleo essencial de Melaleuca alternifolia foi solubilizado com Tween 80 (1\%) e dissolvido em água destilada para a obtenção de soluções nas concentrações de 0,25\%,0,50\%, 1,0\% e 1,5\% (as concentrações, nas tabelas, serão denominadas doses). Como testemunha utilizou-se uma solução de Tween 80 (1\%) sem adição de óleo (0\%). As sementes de sorgo foram tratadas por imersão nas soluções durante cinco minutos e após esse período, foram retiradas (com auxílio de uma peneira) e colocadas sobre papel de filtro para retirada do excesso de solução, em bancadas, em ambiente de laboratório (sem controle de umidade relativa do ar e temperatura). Em seguida, procedeu-se a instalação do teste de germinação (BRASIL, 2009a) e semeadura em casa de vegetação. Para o teste de germinação as sementes foram distribuídas sobre duas folhas de papel "germitest" e cobertas com uma terceira, umedecidas com água na quantidade equivalente a 2,5 vezes o seu peso seco e os rolos foram colocados em germinador na temperatura constante de $25^{\circ} \mathrm{C}$ durante 10 dias. Aproveitou-se a Primeira Contagem de Germinação (PCG) (6 dia) para determinação do vigor. (NAKAGAWA, 1994). Com as sementes tratadas realizou-se também o Teste de Sanidade pelo método do papel de filtro ("Blotter test") com congelamento (BRASIL, 
2009b); foram realizadas cinco repetições com 50 sementes em cada "gerbox" (caixas plásticas transparentes com tampa).

Em casa de vegetação as sementes de cada tratamento foram semeadas em vasos (10 sementes por vaso e cinco repetições) e determinou-se emergência aos 7, 14, 21 28, 35 e 42 dias. Aos 42 dias determinou-se também altura e peso de matéria seca de plântulas. Após o tratamento e secagem natural das sementes, estas foram armazenadas em sacos de papel, em ambiente de laboratório (sem controle de umidade relativa do ar e temperatura) e aos 30 dias foram semeadas em casa de vegetação (idem ao anterior) e determinou-se a emergência aos 7, 14, 21, 28 e 32 dias, quando se determinou também a altura e peso de matéria seca de plântulas.

Os resultados foram analisados em delineamento inteiramente casualizado com quatro repetições para o teste de germinação e cinco repetições para o teste de sanidade e emergência em casa de vegetação; as médias foram comparadas pelo teste de Tukey (5\%).

\section{RESULTADO E DISCUSSÃO}

Os resultados iniciais mostraram que as sementes do cultivar XB6020 apresentavam 95\% de germinação, 3,77g para 100 sementes, 12,2\% de teor de água. O teste de germinação após o tratamento das sementes de sorgo com diferentes concentrações de óleo essencial de melaleuca mostrou que não houve efeito significativo na germinação e no desenvolvimento das plântulas (Tabela 2). Tal fato pode ser visto de forma positiva, mostrando que óleo da melaleuca não interfere negativamente na fisiologia das plantas de sorgo. Já na cultura do girassol, de acordo com Mariano et al. (2013), as mesmas concentrações de óleo de melaleuca proporcionaram melhor emergência em plântulas em condições controladas.

Ainda para sementes de sorgo observou-se, de acordo com Flavio et al. (2014), que sementes tratadas com óleo essencial de Annonna crassiflora nas concentrações de 5, 10 e 15 $\mu \mathrm{l} / \mathrm{ml}$ não apresentaram redução na germinação e índice de velocidade de germinação, no entanto, para o óleo Ocimum gratissimum na concentração de $15 \mu \mathrm{l} / \mathrm{ml}$ houve redução significativa para os dois parâmetros mencionados.

A ausência de fitotoxidez é descrita por outros autores em outras culturas. Segundo Keita et al. (2001) o tratamento com óleo de Glycine $\max ($ L.) Merr. em sementes armazenadas de Phaseolus vulgaris L. não influenciou a germinação e a viabilidade das sementes; também Daronco (2013) verificou que o tratamento de sementes de soja com os óleos essenciais de Eucalyptus globulus e Baccharis trimera (nas concentrações de 10, 20 e 30\%) e Cymbopogon flexuosus (nas concentrações de 10 e 20\%) não afetaram a emergência das plântulas de soja.

Xavier et al. (2012) não encontraram diferenças significativas para a porcentagem de germinação de sementes de Vigna unguiculata tratadas com o óleo essencial de Cymbopogon 
winterianus em diferentes dosagens, no entanto, quando comparadas à testemunha, sementes nãotratadas apresentaram maior porcentagem de germinação.

Tabela 2. Germinação (GE) de sementes, plântulas anormais (P.A), peso de matéria seca de plântulas na primeira contagem (PSPC) e contagem final (PS Final) após tratamento das sementes com diferentes concentrações de óleo de melaleuca (0, 0,25\%, 0,50\%, 1,00\% e 1,50\%).

\begin{tabular}{ccccc}
\hline $\begin{array}{c}\text { DOSES } \\
(\%)\end{array}$ & GE $(\%)$ & $\begin{array}{c}\text { PA } \\
(\%)\end{array}$ & $\begin{array}{c}\text { PSPC } \\
(\mathrm{g})\end{array}$ & $\begin{array}{c}\text { PS Final } \\
(\mathrm{g})\end{array}$ \\
\hline 0 & $75 \mathrm{a}^{1}$ & $21 \mathrm{a}$ & $0,032 \mathrm{a}$ & $0,025 \mathrm{a}$ \\
0,25 & $67 \mathrm{a}$ & $25 \mathrm{a}$ & $0,031 \mathrm{a}$ & $0,025 \mathrm{a}$ \\
0,50 & $74 \mathrm{a}$ & $19 \mathrm{a}$ & $0,032 \mathrm{a}$ & $0,025 \mathrm{a}$ \\
1,00 & $80 \mathrm{a}$ & $16 \mathrm{a}$ & $0,030 \mathrm{a}$ & $0,026 \mathrm{a}$ \\
1,50 & $74^{\mathrm{a}}$ & $22 \mathrm{a}$ & $0,031 \mathrm{a}$ & $0,025 \mathrm{a}$ \\
\hline $\mathrm{CV} \%$ & 10,62 & 36,06 & 2,66 & 3,28 \\
\hline
\end{tabular}
${ }^{\mathrm{T}}$ Médias seguidas da mesma letra, na coluna, não diferem entre si pelo teste de Tukey ao nível de $5 \%$ de
probabilidade.

$\mathrm{Na}$ avaliação de sanidade de sementes (Tabela 3) verificou-se a presença dos fungos Bipolaris spp., Colletotrichum graminicola, Curvularia spp., Aspergillus niger e Aspergillus spp. Para Aspergillus niger e Aspergillus spp., os valores variaram de 1 a $7 \%$ entre as repetições, muito menores do que os verificados para os demais patógenos. Maior incidência de fungos foi observada para Bipolaris spp., Colletotrichum graminicola e Curvularia spp. (Tabela 3).

De acordo com a análise estatística não houve diferença entre as concentrações (tratamentos) para os fungos Bipolaris spp. e Curvularia spp., no entanto, para Colletotrichum graminicola e para sementes "limpas" (foram consideradas sementes limpas aquelas que apresentaram visualmente a ausência de patógenos), ocorreu diferença significativa entre os tratamentos (Tabela 3).

As concentrações do óleo essencial de melaleuca utilizado nos tratamentos $(0 \% ; 0,25 \%$; 0,50\%; $1,0 \%$ e 1,5\%), não apresentaram diferença estatística nos parâmetros analisados, germinação total, plântulas anormais, peso seco em primeira contagem e peso seco final, confirmando que o tratamento de sementes com óleo essencial de Melaleuca não interferem negativamente no desenvolvimento inicial das plantas de sorgo.

De acordo com Mariano (2013) o óleo essencial de melaleuca proporcionou melhor emergência em plântulas de girassol em condições controladas, fato não evidenciado no presente trabalho; foi observado que a Melaleuca não prejudica o desenvolvimento da planta de sorgo.

A avaliação de sanidade de sementes verificou-se a presença dos fungos Bipolaris spp., Colletotrichum graminicola, Aspergillus niger, Aspergillus spp., Curvularia spp., com maior quantidade dos fungos Bipolaris spp., Colletotrichum graminicola, Curvularia spp. Houve diferença entre os tratamentos para Colletotrichum graminicola e para sementes limpas; já para Bipolaris spp. e Curvularia spp. não houve diferenças entre os tratamentos (Tabela 3). 
$\mathrm{Na}$ avaliação da incidência dos fungos de Bipolaris sp. e Curvularia sp. nos diferentes tratamentos foi verificado a mesma incidência desses patógenos, ainda quando empregada a maior concentração de óleo essencial $(1,5 \%)$.

Para o patógeno Colletotrichum graminicola observou-se uma menor incidência do mesmo nas concentrações $0,5 \%, 1 \%$ e $1,5 \%$, que foram iguais entre si e superiores aos tratamentos 0 e 1 (testemunha e 0,25\%). Observa-se também que em relação as sementes limpas houve redução da incidência para as concentrações $0,5 \%$ e $1 \%$, que foram iguais entre si e superiores aos tratamentos 0 e 1 (testemunha e 0,25\%), observou-se também que para a maior concentração $(1,5 \%)$ teve-se o maior número de sementes sem patógenos, ou seja, foi a concentração mais eficiente para o controle (Tabela 3).

Tabela 3. Sanidade de sementes de sorgo, tratadas com óleo essencial de melaleuca (\%) nas concentrações de $0,0,25,0,50,1,0$ e $1,5 \%$.

\begin{tabular}{ccccc}
\hline DOSES & Bipolaris sp. & Curvularia sp. & C. graminicola & Limpas $^{2}$ \\
\hline 0 & $9 \mathrm{a}^{\mathrm{l}}$ & $12 \mathrm{a}$ & $69 \mathrm{a}$ & $7 \mathrm{c}$ \\
0,25 & $5 \mathrm{a}$ & $20 \mathrm{a}$ & $75 \mathrm{a}$ & $7 \mathrm{c}$ \\
0,50 & $6 \mathrm{a}$ & $15 \mathrm{a}$ & $48 \mathrm{~b}$ & $19 \mathrm{~b}$ \\
1,00 & $6 \mathrm{a}$ & $26 \mathrm{a}$ & $34 \mathrm{~b}$ & $27 \mathrm{~b}$ \\
1,50 & $7 \mathrm{a}$ & $16 \mathrm{a}$ & $33 \mathrm{~b}$ & $45 \mathrm{a}$ \\
\hline F & $1,4447^{\mathrm{ns}}$ & 1,8188 & 15,5983 & 47,8554 \\
CV $\%$ & 34,25 & 19,29 & 21,48 & 24,33 \\
\hline
\end{tabular}

${ }^{1} \mathrm{Na}$ coluna, medias seguidas da mesma letra, não diferem entre si pelo teste de Tukey ao nível de $5 \%$ de probabilidade;

${ }^{2}$ Ausência de patógenos no teste de sanidade.

Em trabalho realizado em sementes de soja por Silva et al. (2012) observou-se que os óleos de H. marrubioides, A. gratissima and $C$. verbenacea reduziram a germinação dos conídeos, o crescimento dos micélios e a reprodução de $C$. truncatum, no entanto, não afetaram a viabilidade dos conídeos. Na concentração de 1\%, o controle da antracnose pelos óleos essenciais foi comparável ou mais eficaz que o fungicida comercial Carbendazim. A utilização de óleos de citronela, capim limão, erva cidreira e hortelã pimenta (SARGENTO-BRUN, 2013) mostrou efeitos contra a antracnose corroborando os dados encontrados no presente trabalho com o uso do óleo de melaleuca sobre o C. graminicola.

Estudos com extrato de canela também obtiveram fungitoxidade ao Colletotrichum sp. e Curvularia sp., porém a canela apresentou redução na qualidade fisiológica do sorgo (FLAVIO et $a l .$, 2014), não confirmada com o uso da melaleuca em concentração máxima de $1,5 \%$, entretanto a melaleuca não reduziu a incidência da Curvularia $s p$.

Os testes desenvolvidos na casa de vegetação foram divididos em dois momentos, o primeiro, com a semeadura logo após o tratamento e o segundo teve sua semeadura 30 dias após o tratamento. 
Os resultados obtidos em casa de vegetação logo após tratamento (Tabela 4) mostraram que não houve diferença na emergência e desenvolvimento das plântulas entre as concentrações testadas. Verificou-se que a emergência cessou aos 28 dias após a semeadura, ou seja, o estande tornou-se uniforme. Aos 42 dias realizou-se a determinação de peso de matéria seca e altura de plântulas que também não apresentaram diferenças estatísticas entre os tratamentos.

Tabela 4. Emergência (EC), altura (H) e peso de matéria seca (PMS) de plântulas de sorgo em casa de vegetação após o tratamento das sementes com diferentes concentrações de óleo essencial de melaleuca.

\begin{tabular}{ccccc}
\hline $\begin{array}{c}\text { DOSES } \\
(\%)\end{array}$ & $\begin{array}{c}\text { EC 7 dias } \\
(\%)\end{array}$ & $\begin{array}{c}\text { EC 28 dias } \\
(\%)\end{array}$ & $\begin{array}{c}\text { H 42 dias } \\
(\mathrm{cm})\end{array}$ & $\begin{array}{c}\text { PMS 42dias } \\
(\mathrm{g})\end{array}$ \\
\hline 0 & $40 \mathrm{a}^{1}$ & $38 \mathrm{a}$ & $33,8 \mathrm{a}$ & $0,17 \mathrm{a}$ \\
0,25 & $34 \mathrm{a}$ & $50 \mathrm{a}$ & $35,2 \mathrm{a}$ & $0,180 \mathrm{a}$ \\
1,50 & $22 \mathrm{a}$ & $50 \mathrm{a}$ & $39,8 \mathrm{a}$ & $0,21 \mathrm{a}$ \\
1,00 & $20 \mathrm{a}$ & $32 \mathrm{a}$ & $41,1 \mathrm{a}$ & $0,24 \mathrm{a}$ \\
1,50 & $30 \mathrm{a}$ & $42 \mathrm{a}$ & $35,3 \mathrm{a}$ & $0,18 \mathrm{a}$ \\
\hline $\mathrm{F}$ & 2,3067 & $1,0066 \mathrm{~ns}$ & $0,6827 \mathrm{~ns}$ & 0,54 \\
$\mathrm{CV} \%$ & 41,94 & 40,99 & 23,34 & 50,51
\end{tabular}

${ }^{\mathrm{T}} \mathrm{Na}$ coluna, medias seguidas da mesma letra não diferem entre si pelo teste de Tukey ao nível de $5 \%$ de probabilidade.

Os resultados obtidos na semeadura após 30 dias do tratamento (TABELA 5) mostraram que não houve diferença entre os tratamentos aos sete e 14 dias; observou-se que a emergência cessou aos 14 dias após a semeadura. Houve diferença significativa na altura e peso de matéria seca das plântulas aos 32 dias. Verificou-se que os maiores valores foram obtidos para sementes não tratadas (testemunha).

A fitotoxicidade dos óleos essenciais sobre as plantas é pouco relatada na literatura, pois os estudos, em sua maioria, ainda são feitos "in vitro". Esse resultado pode ser explicado pelo contato do óleo essencial com a semente pelo período de armazenagem de 30 dias, isso pode ter afetado fisiologicamente as sementes, diminuindo sua altura e peso de matéria seca. 
Tabela 5. Emergência (EC), altura (H) e peso de materia seca (PMS) de plântulas de sorgo em casa de vegetação 30 dias após o tratamento das sementes com diferentes concentrações de óleo essencial de melaleuca.

\begin{tabular}{ccccc}
\hline $\begin{array}{c}\text { DOSES } \\
(\%)\end{array}$ & $\begin{array}{c}\text { EC 7 dias } \\
(\%)\end{array}$ & $\begin{array}{c}\text { EC 14 dias } \\
(\%)\end{array}$ & $\begin{array}{c}\text { H 32 } \\
\text { dias } \\
(\mathrm{cm})\end{array}$ & $\begin{array}{c}\text { PMS 32 dias } \\
(\mathrm{g})\end{array}$ \\
\hline 0 & $76 \mathrm{a}^{\mathrm{l}}$ & $84 \mathrm{a}$ & $47,3 \mathrm{a}$ & $0,42 \mathrm{a}$ \\
0,25 & $82 \mathrm{a}$ & $84 \mathrm{a}$ & $35,5 \mathrm{~b}$ & $0,19 \mathrm{~b}$ \\
0,50 & $72 \mathrm{a}$ & $74 \mathrm{a}$ & $40,8 \mathrm{ab}$ & $0,27 \mathrm{ab}$ \\
1,00 & $76 \mathrm{a}$ & $76 \mathrm{a}$ & $34,8 \mathrm{~b}$ & $0,18 \mathrm{~b}$ \\
1,50 & $58 \mathrm{a}$ & $64 \mathrm{a}$ & $37,8 \mathrm{ab}$ & $0,23 \mathrm{ab}$ \\
\hline $\mathrm{F}$ & $1,9902 \mathrm{~ns}$ & $1,7200 \mathrm{~ns}$ & $3,9176^{*}$ & $3,2553^{*}$ \\
$\mathrm{CV} \%$ & 19,62 & 18,51 & 14,61 & 45,87 \\
\hline
\end{tabular}

${ }^{1} \mathrm{Na}$ coluna, medias seguidas da mesma letra não diferem entre si pelo teste de Tukey ao nível de $5 \%$ de probabilidade.

\section{CONCLUSÃO}

O uso do óleo essencial não prejudicou as plântulas de sorgo quando a semeadura foi realizada logo após o tratamento das sementes;

A partir da concentração de $0,50 \%$ do óleo houve controle do Colletotrichum spp. e maior índice de sementes limpas (sem patógenos);

O uso das sementes após 30 dias do tratamento ocasionou redução de peso de matéria seca e altura de plântulas.

\section{REFERÊNCIAS}

BIASI, A. L.; DESCHAMPS, C. Plantas Aromáticas do cultivo a produção de óleo essencial. Curitiba: Layer Studio Gráfico e Editora, 2009.

BRASIL. Ministério da Agricultura, Pecuária e Abastecimento. Regras para análise de sementes. Brasília: Mapa/ACS, 2009a. 399p.

BRASIL. Ministério da Agricultura, Pecuária e Abastecimento. Manual de análise sanitária de sementes. Brasília: MAPA/ACS, 2009b. 200p.

CASTRO C.; SILVA, M. L.; PINHEIRO, A. L.; JACOVINE L. A. G. Análise econômica do cultivo e extração do óleo essencial de Melaleuca alternifolia cheel. Sociedade de Investigações Florestais. Revista Árvore, Viçosa-MG, v.29, n.2, p.241-249, 2005.

CONAB. Companhia Nacional de Abastecimento. Acompanhamento da safra brasileira de grãos v.6, n.9, Junho, 2019.

CORRÊA, B. O.; MOURA, A. B.; DENARDIN, N. D.; SOARES, V. N.; SCHÄFER, J. T.; LUDWIG, J. Influence of bean seed microbiolization on the transmission of Colletotrichum lindemuthianum (Saac and Magn.). Revista Brasileira de Sementes, Londrina, v. 30, p.156-16, 2008.

COSTA. Rodrigo V. da; CASELA, Carlos R.; ZAMBOLIM, Laércio; FERREIRA, Alexandre S. A antracnose do sorgo. Fitopatologia Brasileira, v.28, p.345-354. 2003. 
DARONCO, Maicon V. Óleo essencial no tratamento de sementes de soja (Glycine max L.). [Trabalho de conclusão de curso] Universidade Regional do Noroeste do Estado do Rio Grande do Sul. Ijuí -RS, 2013.

FLAVIO, Nicoletta S. D. S.; SALES, Nilza L. P.; AQUINO, Lucas F. S.; COSTA, Candido A.; SOARES, Eriksen P. S. Extratos aquosos de Cinnamomum zeylanicun e Mentha spicata no tratamento de sementes no sorgo. Horticultura Brasileira, v. 30, n. 2, julho, 2012.

GOMES D. P. Efeito do óleo de nim na qualidade sanitária e fisiológica de sementes de soja. In: ENCONTRO LATINO AMERICANO DE INICIAÇÃO CIENTÍFICA, 12. INIC. Anais [...] São José dos Campos-SP, 2008.

JARDINETTI, Virlene A.; CRUZ, Maria E. S.; MAIA, ALINE J.; OLIVEIRA, JULIANA S. B.; SANTOS, Elisangela M. Efeitos de óleos essenciais no controle de patógenos e na germinação de sementes de milho (Zea mays L.). In: ENCONTRO INTERNACIONAL DE PRODUÇÃO CIENTIFICA, 7. Anais [...]. CESUMAR. Maringá, 2011.

MARIANO, Daiane de C.; GIEBELMEIER, Carmo G.; MARCHIORO JÚNIOR, Marcos A.; ROCHA, Vanessa P. C., FRANCO, Antônio A. N. Utilização de óleo de Melaleuca alternifolia no tratamento de sementes de girassol. In: EPCC ENCONTRO INTERNACIONAL DE PRODUÇÃO CIENTÍFICA CESUMAR UNICESUMAR, 8 - Centro Universitário Cesumar. Anais Eletrônico [...] Editora CESUMAR Maringá - Paraná - Brasil 2013.

MAZZAFERA, P. Efeito alelopático do extrato alcoólico do cravo-da-índia e eugenol. Revista Brasileira de Botânica. v.26 n.2 São Paulo, 2003.

NAKAGAWA, J. Testes de vigor baseados na avaliação de plântulas. In: VIEIRA, R.D., CARVALHO, N.M. (ed). Testes de vigor em sementes. Jaboticabal: FUNEP, 1994. P.49-85.

SARGENTO-BRUM, Rubia B. C.; SANTOS, Gil R.; CASTRO, Henrique G.; GONÇALVES, Clebson; CHAGAS JUNIOR, Aloísio F.; NASCIMENTO, Ildon R. Efeitos de óleo essencial de plantas medicinais sobre a antracnose do sorgo. Bioscience Journal, Uberlandia, v. 29, Supplement 1, nov. 2013. p. 1549-1557.

SILVA, A.C., SOUZA, P.E., MACHADO, J.C., SILVA, B.M., BRASIL, J.E. Effectiveness of essential oils in the treatment of Colletotrichum truncatum infected soybean seeds. Tropical Plant Pathology, v. 37, n.5, p.305-313, Sep. - Oct. 2012.

XAVIER, M.V.A.; OLIVEIRA, C.R.F.; BRITO, S.S.S.; MATOS, C.H.C.; PINTO, M.A.D.S.C Viabilidade de sementes de feijão caupi após o tratamento com óleo essencial de citronela (Cymbopogon winterianus Jowitt). Revista Brasileira de Plantas Medicinais, v.14, $\mathrm{n}^{\circ}$ especial, p.250-254, 2012. 